\title{
Designing Administrative Justice
}

Lorne Sossin

Osgoode Hall Law School of York University, Isossin@osgoode.yorku.ca

\section{Source Publication:}

(2017) 34:1 Windsor Y B Access Just p.87

Follow this and additional works at: https://digitalcommons.osgoode.yorku.ca/scholarly_works

Part of the Administrative Law Commons

c) (1) (8)

This work is licensed under a Creative Commons Attribution-Noncommercial-No Derivative Works 4.0 License.

\section{Repository Citation}

Sossin, Lorne, "Designing Administrative Justice" (2017). Articles \& Book Chapters. 2733.

https://digitalcommons.osgoode.yorku.ca/scholarly_works/2733

This Article is brought to you for free and open access by the Faculty Scholarship at Osgoode Digital Commons. It has been accepted for inclusion in Articles \& Book Chapters by an authorized administrator of Osgoode Digital Commons. 


\section{DESIGNING ADMINISTRATIVE JUSTICE}

\section{Lorne Sossin}

This article explores the adaptation of design thinking to administrative justice. The human centred design perspective has been missing from most debates surrounding the design and reform of administrative tribunals in Canada. As a result, the author asserts that the administrative justice system in Canada at all levels of government (federal, provincial, municipal, and Indigenous) is generally fragmented, poorly coordinated, and under-resourced in relation to the needs of its users and has multiple barriers of entry.

This article is divided into two parts. The first part reviews the development of design thinking in the context of legal services and legal organizations. The second part explores the implications of this development for administrative justice, particularly in the context of the establishment of new tribunals. Several examples of tribunal reform are examined from a design thinking perspective. By way of conclusion, the author suggests the criteria that should be applied to evaluate the design of a new administrative tribunal.

Dans cet article, l'auteur explore l'adaptation de la pensée conceptuelle à la justice administrative. L'approche conceptuelle axée sur la personne est absente de la plupart des débats entourant la conception et la réforme des tribunaux administratifs au Canada. En conséquence, l'auteur fait valoir que le système de justice administrative du Canada de tous les ordres (administrations publiques fédérale, provinciales, municipales et autochtones) est généralement fragmenté et mal coordonné et ne possède pas suffisamment de ressources pour répondre aux besoins de ses utilisateurs, en plus d'être difficilement accessible.

L'article comporte deux parties. Dans la première, l'auteur passe en revue le développement de la pensée conceptuelle dans le contexte des services et organismes juridiques. Dans la seconde, il se penche sur les incidences de ce développement pour la justice administrative, notamment dans le contexte de la création de nouveaux tribunaux. Il présente aussi plusieurs exemples de réformes de tribunaux du point de vue de la pensée conceptuelle. En guise de conclusion, l'auteur suggère les critères qu'il serait souhaitable d'appliquer pour évaluer la conception d'un nouveau tribunal administratif.

\section{INTRODUCTION}

This article explores the adaptation of design thinking to administrative justice. Design thinking - or human-centred design - approaches services and products from the perspective of the user. This perspective too often is missing in the design of administrative tribunals, most of which have been

\footnotetext{
* Lorne Sossin, Dean and Professor, Osgoode Hall Law School, York University. I am grateful to Zachary Hershenfeld for his excellent research assistance and to Margaret Hagan, Nicole Aylwin, Monica Goyal, Nicole Salama, Shannon Salter, Linda Lamoureux, and Michael Gottheil, who all provided helpful input at different stages of this research.
} 
developed top down to serve the needs of a particular policy interest of the government of the day. The administrative justice system in Canada at all levels of government (federal, provincial, municipal, and Indigenous) is generally fragmented, poorly coordinated, and under-resourced in relation to the needs of its users and has multiple barriers of entry.

It has become trite to observe that courts - and most other dispute resolution bodies - have been designed by and for lawyers rather than clients. The rules of evidence, court forms, and jurisprudence all flow from the technical expertise that lawyers acquire, use, and replicate. The effect is to render users who either represent themselves or seek an active role in the process ineffective and alienated. Administrative justice was supposed to be different. As Chief Justice Beverley McLachlin has observed, "[i]n sum, without administrative tribunals, the rule of law in the modern regulatory state would falter and fail. Tribunals offer flexible, swift, and relevant justice. In an age when access to justice is increasingly lacking, they help to fill the gap. And there is no going back."1

Every tribunal that has been established reflects a core premise that an alternative to courts, on the one hand, and government, on the other, is both necessary and beneficial. ${ }^{2}$ Often, tribunals are established in order to deploy a specific expertise beyond legal expertise - for example, the Competition Tribunal seeks to harness economic expertise, while the Human Rights Tribunal seeks to harness antidiscrimination expertise. Some have suggested that administrative justice constitutes a fourth branch of government, distinct from the legislature, judiciary, and the executive. ${ }^{3}$ Most of these tribunals were created to provide more flexibility and greater access than is offered by the courts but sufficient distance from government. Too often, however, even tribunals designed to be informal and flexible have become "legalized" or "judicialized" whether because of growing complexity, anxiety about oversight by courts, or simply because lawyers have not been educated to imagine alternative ways of solving legal problems.

The notion that administrative tribunals are "designed" for particular goals is not new. ${ }^{4}$ Typically, however, discussions of design relate to clarity of statutory mandates, protections of tribunal independence, and the procedures and rules by which a tribunal will function. This literature critiques the structural design features - for example, in the appointments process - which can lead tribunals to be vulnerable to interference and explores the design features that can best enhance the rule of law. ${ }^{5}$ The

1 See "Administrative Tribunals and the Courts: An Evolutionary Relationship," Remarks of the Right Honourable Beverley McLachlin, PC Chief Justice of Canada (Sixth Annual Conference of the Council of Canadian Administrative Tribunals, Toronto, 27 May 2013), online: <http://www.scc-csc.ca/court-cour/judges-juges/spe-dis/bm-2013-05-27eng.aspx $>$.

2 For a history of the development of administrative tribunals in Canada, see Law Reform Commission of Canada, Independent Administrative Agencies, Working Paper 25 (Ottawa: Law Reform Commission of Canada, 1980) 17-32, online: <http://www.lareau-legal.ca/LRCWP25.pdf>.

3 See France Houle, "Constructing the Fourth Branch of Government for Administrative Tribunals" (2007) 37 Supreme Court L Rev 1. See also Lorne Sossin, "The Ambivalence of Administrative Justice in Canada: Does Canada Need a Fourth Branch?" in D Jutras \& A Dodek, eds, The Sacred Fire: The Legacy of Antonio Lamer (Markham: LexisNexis, 2009) 51.

4 See Ron Ellis, “Administrative Tribunal Design” (1987) 1 Can J Admin L \& Prac 134. See also Margot Priest, "Structure and Accountability of Administrative Agencies" (1992) Special Lectures of the Law Society of Upper Canada 11.

5 This critique is particularly apposite in adjudicative rights-oriented tribunals. See Ron Ellis, Unjust by Design Canada's Administrative Justice System (Vancouver: UBC Press, 2013). 
design concerns I explore tend to arise subsequent to this "legal design" phase, once legislation to establish a tribunal and demarcate its powers has been enacted. It is often at this point that the functional design questions around how the tribunal actually will work come into focus (though, of course, attention to the lived experience of users in the legal design phase is also highly desirable).

When considering new tribunals or adding new mandates to existing tribunals, a number of design questions are highlighted. Should the tribunal be virtual (such as the Civil Resolution Tribunal of British Columbia, examined elsewhere in this volume) $?^{6}$ If physical, where should the tribunal be located (in one central location or in many satellite storefronts), and how will its services be accessed (online, by phone, in person, or in combinations of all of these)? How many languages will the tribunal services be offered in, and how will it accommodate people living with physical and/or cognitive disabilities or other impairments? How much will it cost people to use the tribunal, and will all individuals pay the same amount? How will its staff and members be trained to meet the needs of users? Will it adopt an adversarial system of dispute resolution, a mediation or arbitration process, or a more inquisitorial set of procedures?

The questions suggested by design thinking are starkly distinct from the questions typically asked about tribunals within a policy context or within the doctrines of administrative law and statutory drafting, which often relate to its jurisdiction, authority, rules, expertise, powers, method of appointment, and independence. Further, under the current model, questions of statutory authority, on the one hand, and budget and staffing for a tribunal, on the other, are bifurcated. In a design-thinking framework, bifurcating these key dynamics is neither possible nor desirable. Rather, design thinking puts a premium on holistic frameworks that link together issues of statutory jurisdiction with issues of user need, including resources, infrastructure, staffing, training, and administrative structures. In short, tribunals have historically been structured through a top-down, policy-making exercise, while design thinking leads by definition to a bottom-up process of determining the key features and functions of administrative tribunals.

This article is divided into two parts. In the first part, I review the development of design thinking in the context of legal services and legal organizations. In the second part, I explore the implications of this development for administrative justice, particularly in the context of the establishment of new tribunals and situate the evolution of design thinking in Canadian administrative justice within broader trends in the common law world. I conclude with the criteria that I suggest should be applied to determine if the design of a new administrative tribunal is successful.

\section{DESIGN THINKING AND LAW}

As Margaret Hagan has written, design methodologies have put an emphasis on quick prototyping, frequent testing, and, above all, a focus on making services that users will love to use. ${ }^{7}$ Nicole Aylwin explains the approach in the following terms:

6 See Shannon Salter's reflections in S. Salter, “ODR and Justice System Integration: B.C.'s Civil Resolution Tribunal” (2017) 34 Windsor Yearbook of Access to Justice 111.

7 "CBA Futures Chat: Law and Design," Slaw (16 June 2014), online: <http://www.slaw.ca/2014/06/16/cba-futures-chatlaw-and-design/>. 
[Design thinking] involves immersing yourself in the problem you are trying to solve, working with the people experiencing the problem, experimenting with solutions, and most importantly, lowering your defenses and opening yourself and your design team up to candid and uncensored feedback about what you are doing wrong (and hopefully some things you are doing right) $!^{8}$

The methodology of design may differ across settings (for example, designing a product is distinct from designing a service and so on) but generally involves these six steps:

1. begin with empathy in order to fully understand the users of the services and the service ecosystem;

2. define the problem collectively and from a user perspective;

3. brainstorm a multitude of potential solutions;

4. choose the best solutions to prototype;

5. test the prototypes; and

6. repeat steps 4 and 5 until the product or service is ready to implement (though the process of adjustment and adaptation in relation to need is continuous). ${ }^{9}$

Another way of understanding design thinking is set out by Margaret Hagan:

1. discover - what is the landscape? (understand the challenges situation and the stakeholders);

2. synthesize - what is your mission? (define and map the users and problem statement for which you will be designing);

3. build - what ideas may work? (generate possible solutions for the problem and prototype them);

4. test - are the ideas worthwhile? (test promising prototypes with your users and in live situations); and

5. evolve - how to move forward? (process the feedback, edit your prototypes, and vet them). ${ }^{10}$

IDEO, a design company, has developed a "toolkit" for human-centred design adopting elements of the above approaches (such as the importance of empathy for the user experience and revising design features based on observing user behaviour and integrating dynamic feedback). ${ }^{11}$ According to IDEO,

$8 \quad$ Nicole Aylwin, "Human Centred Design and the Justice System" (6 June 2016), online:

$<$ http://www.slaw.ca/2016/06/06/human-centered-design-and-the-justice-system-lessons-from-the-field/>.

9 Winkler Institute for Dispute Resolution, online: <http://winklerinstitute.ca/practice-pilots/>.

10 Margaret Hagan, "Next Gen Legal Services: Possibility of Legal Design” (April 2015), online: <http://www.legaltechdesign.com/>.

11 IDEO, "Design Kit: The Human Centered Design Toolkit," online: <https://www.ideo.com/by-ideo/human-centereddesign-toolkit>. 
"designers trust that as long as they stay connected to the behaviours and needs of the people they're designing for, their ideas will evolve into the right solution. In other words, they let the end-user tell them what they need to focus on building." ${ }^{.2}$ As these versions of design methodology emphasize, design thinking is focused primarily on process. The focus of design thinking is usability, including the ability to attract people to use a service because it engenders other positive attributes (whether because it is natural to use, easy to access, customized to a person's distinct needs or identities, or simply because it is engaging). In this sense, a well-designed experience is not only functional, but also engaging and appealing. Design thinking responds to a "crisis of legitimacy" in the legal system arising from the yawning gap between those who have access to legal services and those who do not. ${ }^{13}$

In the legal context, the design approach has focused in particular on how people access legal information. For example, Margaret Hagan's Legal Design Studio projects have involved the "Mobile Legal Advocate," which guides a person through the steps to access legal services by texting or social media platforms. The San Francisco Housing Law Triage aims to empower citizens facing eviction to navigate the legal system to better understand and assert their rights in that system. The Plea Agreement Project seeks to assist criminal defendants to better understand plea offers. Finally, the Immigration Navigator supports potential immigrants and refugees by providing checklists, timelines and reminders for different stages of the immigration approval process.

Early examples of the application of design thinking to law in Canada have focused on access-tojustice and family law reform settings and suggest important insights for how to apply design thinking in the context of administrative justice. The Family Justice and Mental Health Social Lab, for example, aims to improve the experience of users of the family justice system who deal with mental health challenges. By bringing in and gathering the perspectives of social workers, lawyers, mental health workers, psychologists, family physicians, academics, and children and youth advocates, the Family Justice and Mental Health Social Lab has developed three pilot projects that address family justice and mental health needs from a user perspective. These include: Track My Life, a mobile phone app that provides access for youth to their basic information such as health card number, social insurance number, medical records, court dates, driver's license number, school records, and so on and access to important data and records; the Family Support Table, an alternative dispute resolution option that brings in a network of professionals such as psychologists, educators, financial planners, faith-based intermediaries, and dieticians, among others, to work with families who are struggling with mental health and family justice issues; and Help, Educate, and Link Professionals, a confidential communication network that provides answers to questions by fellow professionals such as psychologists, lawyers, pharmacists, family doctors, and social workers who may need some general guidance or information related to family justice and mental health.

The Yukon Family Justice Design workshop incorporated ideas of human-centred design in order to brainstorm and prototype ideas to improve the experiences of clients in the family justice system. One particular improvement was in response to users indicating that completing the necessary forms often induced stress and anxiety. The workshop and its human-centred design process came up with the

Ibid.

13 For discussion, see Susan Ursel, "Building Better Law: How Design Thinking Can Help Us Be Better Lawyers, Meet New Challenges and Create the Future of Law," in this volume. 
foundation for the Yukon Simplified Form Innovation Project, which aims to solve this user issue. In addition to these initiatives, there have been other platforms that have incorporated human-centred design methodology into legal practice. The Court Messaging Project is aimed at making the court system more navigable and improving a user's sense that the legal system is fair, comprehensible, and user-friendly. The tool allows for the court to send automated messages with reminders and tips for litigants regarding their upcoming obligations. ${ }^{14}$ The Plea Agreement Project redesigned lengthy plea agreements into a clear, visual design, in terms that a non-lawyer can understand. ${ }^{15}$ The Navocado Project seeks to enhance the legal processes by converting long documents into "interactive, techenabled, and user-friendly guides."16

These pilot initiatives indicate the importance of linking the policy aims of administrative bodies to multi-disciplinary and user-centred processes. These operational goals may relate to access generally (for example, intake forms and so on) or to specific aspects of the policy sphere the tribunal governs or the kinds of people most likely to seek out the tribunal. While some aspects of human-centred design do not relate to specific technology initiatives in the delivery of legal information or services, the innovation sector in legal services is a key driver of the design-thinking movement in law. So much so that the focus of some organizations dedicated to access to justice are focusing on cohering and coordinating technical standards for litigation portals in order to ensure technology does not simply reproduce and exacerbate many of the current dysfunctions in the justice system (complexity, asymmetries of information and influence, barriers of entry, and so on). ${ }^{17}$

There are other important aspects of design thinking relevant for legal systems generally. A key aspect relates to how legal information is communicated. Design thinking focuses not just on putting accurate information in places where it can be found (whether a text or monograph in a library or, more recently, updated websites and legal databases) but also on how such information can attract the users' attention and how well such information is then connected to aspects of a legal process. In other words, the traditional separation between legal information (what are my rights?) and legal process (how can I assert or protect those rights?) is blurred and ultimately eliminated in a designed approach to dispute resolution. Design thinking also asks potentially disruptive questions about how information is conveyed in legal settings. For example, most legal information (and legal advocacy, for that matter) is communicated using the written word. This approach was well suited to a culture based on written communications. In an increasingly visual and aural culture, will podcasts, animated images, and documentary film take the place of written documents in legal communications? How might legal settings take advantage of interactive digital technology to create usable, satisfying communication experiences?

All of these efforts are aimed at improving service offerings and relationships with the users of the legal system and also at developing a particular responsive and innovation-oriented culture within the

4 Legal Design Lab, “The Court Messaging Project," online: <http://www.legaltechdesign.com/CourtMessagingProject/>.

15 Legal Design Initiative, "The Plea Agreement Project," online: <http://legaltechdesign.com/ThePleaAgreementProject/>.

16 Legal Design Lab, "Navocado," online: $<$ http://legaltechdesign.com/legalnavigators/>.

17 See National Center for State Courts, "Report: Building A Litigant Portal: Business and Technical Requirements" (2015), online: $<$ http://www.srln.org/node/629/report-building-litigant-portal-business-and-technical-requirements-ncsc2015>. 
tribunals themselves (including tribunal staff and tribunal members). This culture includes the ability to identify, reflect upon, and attempt to improve inefficiencies or "fail points" in current practices and foster collaboration across institutional silos or professional/disciplinary boundaries. In other words, the best way to resolve a dispute before a tribunal may involve a social worker rather than a lawyer and the best way to design a tribunal may draw on expertise from retail and hospitality sectors as much as courthouses and government agencies. The goal is an experimental culture that embraces change and empowers all members of the organization to solve problems and play an active role in improving tribunal operations. In the following sections, I apply some of these design thinking frameworks to contexts of administrative justice specifically. In so doing, I attempt to set the stage for a new kind of criteria for success by which administrative justice ought to be evaluated.

\section{DESIGNING A NEW FRAMEWORK FOR ADMINISTRATIVE JUSTICE}

Some aspects of design thinking apply to all dispute resolution entities, whether courts, tribunals, and all dispute resolution mechanisms (mediation, negotiation, arbitration, adjudication, and so on). ${ }^{18}$ Other aspects, I suggest, however, are distinctive to administrative justice and its policy environments. In other words, while all dispute resolution bodies and mechanisms seek to provide solutions to people's problems, the entities and mechanisms that are part of administrative justice also seek to advance a particular policy goal. A human rights tribunal is part of a scheme, for example, to create a society free from discrimination. A labour board is intended not just to resolve disputes but also to advance other policy goals (in Ontario, for example, the Labour Relations Act empowering the board aims not just "to promote the expeditious resolution of workplace disputes" but also "to encourage co-operative participation of employers and trade unions in resolving workplace issues" and "to recognize the importance of workplace parties adapting to change," among other priorities), and, for this reason, its tripartite dispute resolution mechanisms constitute an appropriate design feature for its policy goals. ${ }^{19}$

This policy aspect of administrative justice plays a key role in the design process. It also suggests the need for perspectives other than law/dispute resolution to inform the design of tribunals. In other words, designing administrative justice arguably should always include a legal perspective but should never include only a legal perspective. Multidisciplinary approaches to dispute resolution are inherent to the sphere of administrative justice. For example, a consent/capacity board cannot be designed with only legal rights in mind, but needs to also consider medical and social considerations. These perspectives relate not only to the rules of practice for such a body but also to how vulnerable communities will access the board and how the interests of vulnerable individuals are ensured and how the medical and social context of such individuals are appropriately considered.

Beyond the specific policy goals of the statutes empowering administrative tribunals, all administrative tribunals reflect important policy choices not to leave particular kinds of disputes to the courts, on the one hand, or to the government itself, on the other hand. Designers of administrative justice must also take this choice as a point of departure. For example, if a tribunal is designed to mirror a court in every respect, then, arguably, it has failed to reflect the legislature's choice to assign disputes

18 See e.g. W David Ball, "Redesigning Sentencing” (2014) 46 McGeorge L Rev 817.

19 Labour Relations Act, SO 1995, c 1, Sched A. 
to the tribunal and not to a court in the first place. Similarly, if the tribunal is designed with the same policy motivations and discretion as a government department, then it has failed to reflect the choice to create a body other than a government department to resolve the dispute. Thus, the critical design question for every tribunal is how, in its process, the distinctiveness of tribunals both from courts and government is clear.

Finally, it is important to see administrative justice in the context of accessibility. Virtually all tribunals are justified as desirable models of dispute resolution because they can provide enhanced accessibility relative to courts and other alternatives. Tribunals are often justified as providing less expensive, less formal, and more specialized dispute resolution. In Rasannen v Rosemount Instruments, Justice of Appeal Rosalie Abella (as she then was), writing for the Ontario Court of Appeal, describes the role and function of administrative tribunals as follows:

They were expressly created as independent bodies for the purpose of being an alternative to the judicial process, including its procedural panoplies. Designed to be less cumbersome, less expensive, less formal and less delayed, these impartial decision making bodies were to resolve disputes in their area of specialization more expeditiously and more accessibly, but no less effectively or credibly. ${ }^{20}$

Sir Andrew Leggatt's comprehensive 2001 Report of the Review of Tribunals by Sir Andrew Leggatt: Tribunals for Users - One System, One Service (Leggatt report), which made recommendations for the reform of Britain's tribunal system, commented:

Choosing a tribunal to decide disputes should bring two distinctive advantages for users. First, tribunal decisions are often made jointly by a panel of people who pool legal and other expert knowledge, and are the better for that range of skills. Secondly, tribunals' procedures and approach to overseeing the preparation of cases and their hearing can be simpler and more informal than the courts, even after the civil justice reforms. Most users ought therefore to be capable of preparing and presenting their cases to the tribunal themselves, providing they have the right kind of help. Enabling that kind of direct participation is an important justification for establishing tribunals at all. ${ }^{21}$

While not invoking design thinking by name, Leggatt's analysis builds on a kindred set of values, noting, for example, "[i]t should never be forgotten that tribunals exist for users, and not the other way round. No matter how good tribunals may be, they do not fulfil their function unless they are accessible by the people who want to use them, and unless the users receive the help they need to prepare and present their cases."22

20 Rasanen v Rosemount Instruments Ltd (1994) 17 OR (3d) 267 (CA).

21 Andrew Leggatt, Tribunals for Users: One System, One Service-Report of the Review of Tribunals (March 2001) at para 1.2, online: <http://webarchive.nationalarchives.gov.uk/+/http://www.tribunals-review.org.uk/>.

$22 \quad$ Ibid at p.6. 
Tribunals, by their very nature, are flexible in their operational requirements, varying widely in size, process, and mandates to address their particular statutory and policy contexts. There are approximately 235 tribunals in Ontario alone. ${ }^{23}$ As Peter Cane has observed, far too little attention in public law has been devoted to administrative justice. ${ }^{24}$ While, in some jurisdictions, such as the United Kingdom, adjudicative tribunals fall under the supervision of the judiciary, the Supreme Court of Canada has confirmed that all administrative tribunals in Canada are a part of the executive branch of government, established by statute to further a policy objective. ${ }^{25}$ Governments in Canada continue to experiment with different organizational models in their attempts to balance the policy mandate of tribunals with their adjudicative function while working to improve accessibility for users and the quality of decision making. As Jamie Baxter and I asserted in a study of Ontario's move to tribunal "clusters," referring to tribunals as part of an administrative justice "system" may reflect more of an aspiration than a reality:

The need for such change is evident. Claimants who come to administrative tribunals in Canada, as elsewhere, expecting a convenient forum to resolve their problems may discover that institutional resources and expertise, their own knowledge of the system, and their statutory entitlements and legal rights are fragmented between bodies with diverse norms and mandates. At least from a birds-eye view, the tribunal "system" now looks more like an ad hoc assortment of isolated institutions than a coherent system of justice. Increasingly, it seems that the very structures and modes of organization behind the delivery of administrative justice may actually post barriers for users, even as they separate individual tribunals from the shared knowledge, practices and infrastructure that a more rational and explicitly coordinated administrative justice system would have to offer. The challenge now squarely in front of reformers is to identify suitable approaches to institutional change that will thread these disparate elements into a more coherent whole. $^{26}$

While Canada remains a patchwork quilt of administrative bodies (even if some steps towards coherence are evident, as discussed below in the context of the Administrative Tribunals Support Service), other jurisdictions have moved towards setting out shared design principles and shared evaluative standards for tribunals. For example, the New Zealand Law Reform Commission, in a thorough review of that country's tribunal systems, identified a number of desirable characteristics that individual tribunals, or systems of tribunals, should exhibit, including:

23 Ministry of the Attorney General, Guidelines for Administrative Tribunals, online:

$<$ https://www.attorneygeneral.jus.gov.on.ca/english/justiceont/french_language_services/services/administrative_tribuna ls.php>.

24 See Peter Cane, Administrative Tribunals and Adjudication (Oxford: Hart Publishing, 2009); Peter Cane, 'Judicial Review in the Age of Tribunals' (2009) 2009(3) Public Law 479.

25 Ocean Port Hotel Ltd v British Columbia (General Manager, Liquor Control and Licensing Branch), 2001 SCC 52 at paras 21-24 [Ocean Port].

26 See Lorne Sossin \& Jamie Baxter, "Ontario's Administrative Tribunal Clusters: A Glass Half-Full or Half-Empty for Administrative Justice" (2012) 12 Oxford Commonwealth LJ 157 at 162. 
- public accessibility, both in terms of costs and in public awareness of opportunities to seek redress;

- membership and expertise appropriate to the subject matter;

- actual and apparent independence;

- procedural rules that secure the observance of natural justice but that will also be simpler and less formal than the courts (and may be more inquisitorial);

- sufficient powers to carry out their functions, which are proportionate to those functions;

- appropriate avenues for appeal or review of tribunal decisions in order to ensure oversight and error correction; and

- $\quad$ speedy and efficient determination of cases. ${ }^{27}$

Canada also appears to lag behind with respect to a detailed literature on tribunal users, which other countries in the common law world have developed. ${ }^{28}$

The Leggatt report in the United Kingdom suggests that failure to achieve the advantages inherent in a tribunal system most often arises from inadequacies in tribunal design, and it suggests that tribunal design focus on:

- structural coherence, involving considerations such as avoiding isolation and narrowness of outlook, sufficient investment in training, attracting, and retaining suitable staff, and effective systems of administrative support;

- independence, including public perception of independence, which is associated with appointment processes, security of tenure, and whether the tribunal is administered by a department with an interest in the outcome of decisions; and

- user friendliness, which will reduce the need for professional representation, through such elements as information for users as well as independent help and support. ${ }^{29}$

While a standard for evaluating the performance of administrative tribunals has yet to emerge in Canada, ${ }^{30}$ the Council of Australasian Tribunals [COAT] has developed a framework for tribunal

27 New Zealand Law Reform Commission, “Tribunals in New Zealand” (January 2008) at 2.67, online:

$<\mathrm{http}: / / w w w . l a w c o m . g o v t . n z /$ sites/default/files/projectAvailableFormats/NZLC\%20IP6.pdf $>$.

28 See e.g. Hazel Genn, Ben Lever, and Lauren Gray, Tribunals for Diverse Users (London: Research Unit, Department for Constitutional Affairs, Justice Rights and Democracy, 2006), online:

$<$ http://www.dca.gov.uk/research/2006/01_2006.pdf $>$. For a Canadian example of this kind of study, see Marcia Valiante \& WA Bogart, "Helping Concerned Volunteers Working Out of Their Kitchens: Funding Citizen Participation in Administrative Decision Making" (1993) 31 Osgoode Hall LJ 687. See also Council of Canadian Administrative Tribunals, Literacy and Access to Administrative Justice in Canada: A Guide for the Promotion of Plain Language (Ottawa: Council of Canadian Administrative Tribunals, 2005).

29 See Legatt, supra note 21. See also L Sossin, "Reflections on the UK Tribunal Reform: A Canadian Perspective" (2011) 24 Can J Admin L \& Prac 17.

30 Various attempts at developing such a standard have been undertaken in some Canadian jurisdictions and settings. See e.g. Society of Ontario Adjudicators and Regulators, "Toward Maintaining and Improving the Quality of Adjudication: 
excellence in 2012 (revised in 2014), which has been widely accepted as an evaluative framework for administrative tribunals. ${ }^{31}$ COAT's approach to tribunal excellence has three broad dimensions:

- $\quad$ predictable, just decisions;

- procedural justice; and

- the delivery of a fair and efficient dispute resolution service.

These three dimensions of tribunal excellence are reflected in the COAT framework. Predictability relates to consistency and certainty - users who appear before different panels or locations of a tribunal or different formats - online or in person - ought to have the same principles applied in similar ways. In other words, different tribunal members faced with the same facts should, broadly speaking, reach the same outcome. A 'just decision' is one based solely on the application of the relevant law to the facts of the case and is inconsistent with bias, ulterior motives, or arbitrary factors. Procedural justice includes fairness, accessibility, and user satisfaction (even and especially among losing parties in a dispute). These factors together contribute to the perceived legitimacy of the justice system and the application of public authority.

Richard Moorhead, Mark Sefton, and Lesley Scanlan found that five process-oriented factors contributed to user satisfaction:

1. the expectations of, and information provided to, participants;

2. the quality of participation granted to participants (that is, the extent to which, and the process through which, participants are able to get their story out in a way they view as being accurate and fair);

3. the quality of treatment and, in particular, the respect shown to the participant during their time at the tribunal;

4. issues of convenience and comfort, including timeliness and efficiency; and

5. judgments about tribunal members and staff - whether they were perceived as helpful and empathetic. $^{32}$

In light of these core values and a user-centred approach, COAT's framework identifies eight measures of excellence against which all tribunals should be assessed:

SOAR Recommendations for Performance Management in Ontario's Administrative Justice System” (1996) Can J Admin L \& Prac 179. See also Steven Hoffman \& Lorne Sossin, "Evaluating the Impact of Remedial Authority: Adjudicative Tribunals in the Health Sector" in K Roach \& R Sharpe (eds), Taking Remedies Seriously (Montreal: Canadian Institute for the Administration of Justice, 2009) 521.

31 COAT Framework of Tribunal Excellence, online: <http://www.coat.gov.au/images/downloads/INTL\%20COAT\%20FRAMEWK\%20TRIB\%20April\%202014.pdf>.

32 Richard Moorhead, Mark Sefton \& Lesley Scanlan, "Just Satisfaction? What Drives Public and Participant Satisfaction with Courts and Tribunals," Ministry of Justice Research Series 5/08, Cardiff Law School, Cardiff University (March 2008). 
1. independence;

2. leadership and effective management;

3. fair treatment;

4. accessibility;

5. professionalism and integrity;

6. accountability;

7. efficiency; and

8. client needs and satisfaction.

The assessment process consists of detailed survey questions on each of these eight factors, resulting in an overall "score." The framework includes a variety of elements that overlap with human-centred design approaches (from client needs to accessibility and fair treatment) as well as areas that track more conventional top-down approaches to administrative justice. The Ontario Bar Association established a working group on the COAT framework, and it has already been adopted in the planning cycle of several tribunals in Canada. ${ }^{33}$

Tribunal design must also take into consideration other general legal constraints. Such constraints, as suggested above, must begin with the jurisdiction afforded a tribunal by statute. Statutes (or regulations issued under such statutes) may also address methods or frameworks for dispute resolution and the criteria by which disputes will be resolved. ${ }^{34}$ Additionally, some jurisdictions have statutes of general applications to tribunals, such as British Columbia's Administrative Tribunals Act or Ontario's Statutory Powers Procedures Act $[S P P A] .{ }^{35}$ The SPPA sets out basic procedural requirements for tribunals when holding hearings - for example, with respect to notice requirements, written or electronic hearings, admissible evidence, parties to the proceeding, and many other matters. ${ }^{36}$ Ontario's Adjudicative Tribunals Accountability, Governance and Administration Act [ATAGAA] is another example of general legislation affecting tribunals, which sets out the requirements for public accountability documents, such as service standards, business plans, consultation policies, mandate and mission statements, and member accountability frameworks. ${ }^{37}$ The $A T A G A A$ outlines standards for member appointment processes, permits the creation of tribunal clusters; and includes other requirements aimed at promoting tribunals that are, "accountable, transparent and efficient in their operations while remaining independent in their decision-making." 38 In light of these backdrops, and the methodology of human-centred design discussed above, I propose the following framework for evaluating new or restructured administrative tribunals.

33 On the relationship between developments in Australia, Canada, and other peer jurisdictions in areas of administrative justice, see L Sossin, "Administrative Justice in an Interconnected World," Australian Institute for Administrative Law (2014) 27 Can J Admin L \& Prac 53.

34 See Ontario Bar Association, online: $<$ https://www.oba.org/Member-Login?ReturnUrl=\%2fSections\%2fAdministrativeLaw\%2fArticles\%2fArticles-2013\%2fApril-2013\%2fNEW-OBA-WORKING-GROUP-ASSIGNMENT-A-Frameworkfor- $\mathrm{T}>$.

35 BC Administrative Tribunals Act, SBC 2004, c 45; Statutory Powers Procedure Act, RSO 1990, c S22 (SPPA).

36 SPPA, supra note 34.

37 SO 2009, c $33(A T A G A A)$.

38 Ibid, Sched 55, s 1 . See also discussion of ATAGAA in Sossin \& Baxter, supra note 25. 


\section{A. Identifying the Needs}

In the past, the need for new initiatives in administrative justice often arose through a top-down process of policy leadership. The justification for these initiatives was often by and for elites and related to arguments about accountability, independence, and expertise. For example, the McRuer report in $1968^{39}$ articulated a model of public oversight for self-governing professions that provided the groundwork for the establishment of the Ontario Health Professions Appeal and Review Board. ${ }^{40}$ The actual design and jurisdiction of the tribunal established through the Health Disciplines Act ${ }^{41}$ in 1974 was the result of a political compromise between the government, self-regulating health professions, and other experts and advocates. ${ }^{42}$ While the needs of patients or "the public" may have been invoked during these discussions, the process of negotiating the structure and mandate of the tribunal itself was conducted behind closed doors, and few members of the public beyond representatives of health professionals were involved in any way in the process.

From a design perspective, identifying the needs to which a particular tribunal or other administrative body will respond ought to involve a collective, transparent, and empathetic needs assessment. This process can (and arguably must) also involve a process of refining the public interest and ensuring the democratic legitimacy of any resulting legislation of governmental action. The combination of a userfocused needs assessment, together with a policy-making process and the democratic legitimacy inherent in legislation empowering new or reformed tribunals is a distinct feature of designing administrative justice.

\section{B. Setting out Purposes and Principles}

The public interest inherent in the design of administrative justice requires a transparent articulation of the purposes and principles of new or reformed administrative bodies. The process of setting out purposes and principles itself flows from the needs assessment and policy process indicated above and should involve consultations and user participation to the extent possible. In virtually every case, the articulation of purposes and principles will include a clear justification for why the administrative body and its authority/discretion is necessary and also a specific account of the extent to which the administrative body has a mandate to be accessible to users.

\section{Determining the Best Model to Advance the Purposes and Principles}

With needs identified and the purposes and principles articulated, the third aspect of the design framework for administrative justice involves determining the best model to address those needs, purposes, and principles. While a caveat is needed about over-generalizing in relation to such a diverse sphere, it is fair to say that administrative bodies often are located in office buildings in the midst of

39 Report of the Ontario Royal Commission Inquiry Into Civil Rights (Toronto: Queen's Printer, 1968) (the “McRuer Report")

40 See the Health Professions Appeal and Review Board's (HPARB) submission to the Health Professions Regulatory Advisory Council (2008), Appendix A, online: <http://hprac.org/en/projects/resources/hprac-1457May30HPARB.pdf >. I should add that I serve as a member and designated vice-chair of the HPARB, and none of the views expressed herein reflect those of the board.

41 The Health Disciplines Act, 1974, SO 1974, c 47.

42 Ibid. 
other public sector or broader public sector office complexes (ministries, agencies, and so on). They are rarely marked at street level, rarely located where most of their users live and work, and their look and feel might be characterized charitably as "bureaucratic." Those fully capable of navigating a dispute resolution process online immediately are required to show up in person at a date weeks or months away, while those with complex needs who require in-person support to navigate the process effectively are too often routed to a call centre or a website. These dysfunctional situations are the product of design flaws. The flaws, moreover, flow not just from the absence of meaningful roles for users in the process (the focus of the design movement) but also from the presence of structures that impair well-designed outcomes. For example, those who work carefully on the needs assessment or on the development of purposes and principles, typically are not those that decide where public agencies are located or how their physical plant (or information technology) is organized. Different people working on different problems in different places with different expertise and incentives are unlikely to collaborate on design solutions.

The structures of administrative justice are particularly ill-conceived for the demands of design thinking. All administrative bodies at the federal or provincial/territorial level have a host or affiliated ministry, responsible not only for submitting budgets on behalf of those bodies but also for key aspects of public administration relating to these bodies (discussed further below in relation to the case study of a new federal structure intended to integrate and modernize the support of multiple tribunals). These may or may not be the same ministries responsible for developing the legislation empowering such administrative bodies and the design process underlying a tribunal's jurisdiction, scope, and policy context. Different ministries, in turn, administer government services, government infrastructure, and government real estate. So it is understandable that a new tribunal may have one group in government devoted to designing the mandate of the tribunal, another group in government focused on the budget and staffing of the tribunal, and still another group looking for appropriate and cost-effective space in light of the existing stock of real estate, all before a single member of the tribunal has been appointed or a user of the tribunal has sought out its services.

This structural divide means the practice of administrative justice too often undermines its purposes and principles. This is not to say that the structures of administrative justice themselves have not been designed but, rather, that their design reflects other priorities and constraints. For example, moving tribunals from host ministries to "clusters," as occurred in Ontario, was intended to create both economies of scale (to enhance the capacity of the resulting cluster to meet the needs of users of the tribunals that make up the cluster) and to enhance the independence of tribunals from the government itself. These administrative law protections are reflected in the COAT framework and in the jurisprudence on administrative law in Canada, which includes the independence and impartiality of administrative decision makers as a key aspect of the duty of fairness and the procedural rights for those affected by administrative decisions. In focusing the debate in administrative justice more on design goals, it is important not to lose sight of the realities of government and the importance of those administrative law protections.

One reality is the constitutional constraint in Canada limiting the subject matter that can be assigned to a tribunal. One aspect of this constraint is federalism, and, thus, in some areas tribunals are created for overlapping purposes (labour tribunals and human rights tribunals, among others) to reflect Canada's distinct division of powers. Another, more specific standard relating to tribunals is the constraint on 
governments transferring certain powers from superior courts to administrative tribunals. Since 1981, the leading case on this interpretation of section 96 of the Constitution Act, 1867, and the power of provincial legislatures to confer jurisdiction to administrative tribunals has been Reference re Residential Tenancies Act [Residential Tenancies] in $1981 .^{43}$ In his decision, Justice Brian Dickson (as he then was) formulated a three-part test to determine whether the power conferred to an administrative tribunal is constitutional. The test included the following procedure.

1. A determination is made of "whether the power or jurisdiction conforms to the power or jurisdiction exercised by superior, district or county courts (a section 96 court) at the time of Confederation."

2. If yes, a determination of "whether the function in question is 'judicial' in its institutional setting" as opposed to policy-making functions.

3. If yes, a determination is made on the "context in which the power is exercised" whether the "judicial powers" are merely ancillary to the general administrative functions assigned to the tribunal or necessarily incidental to the achievement of a broader policy goal of the legislature rather than the "sole or central function of the tribunal":

a. If so, the conferring of judicial power is valid.

b. If not, the tribunal "is said to be operating like a section 96 court," and the grant of power is invalid.

This test was moderately amended in Sobeys Stores Ltd v Yoemans in 1989 by Justice Bertha Wilson, who stated that the characterization of the "powers" in part 1 of the test "should highlight the type of dispute rather than the type of remedy sought" and must be applied narrowly. ${ }^{44}$ She treated this act of characterization as a preliminary step to the first stage of the three-stage test from Residential Tenancies. Wilson J also clarified that the first step in the Residential Tenancies test must refer to powers that were exclusive to section 96 courts at the time of Confederation, not "shared," meaning "broadly coextensive" with inferior courts. ${ }^{45}$

Reference re Amendments to the Residential Tenancies Act in 1996 provided further clarifications to the three-part test. ${ }^{46}$ The court found that the Act, which confers powers to adjudicate disputes between landlords and their residential tenants exclusively to the director of residential tenancies with the power to appeal to a Residential Tenancies Board, did not violate section 96 of the Constitution Act, 1867. The result was concluded in part one of the test, as the jurisdiction to hear disputes between landlord and tenants was not within the exclusive core jurisdiction of superior courts in 1867. Chief Justice Antonio Lamer explained that the "core jurisdiction" for the purposes of this test is "very narrow ... includes

43 Constitution Act, 1867, 30 \& 31 Vict, c 3, reprinted in RSC 1985, App II, No 5.Reference re Residential Tenancies Act, [1981] 1 SCR 714.

44 Sobeys Stores Ltd v Yeomans, [1989] 1 SCR 238, at para 21 [Sobeys Stores]. See also MacMillan Bloedel Ltd v Simpson [1995] 4 SCR 725.

45 Sobeys Stores, supra note 41 at para 31.

46 Reference re Amendments to the Residential Tenancies Act, [1996] 1 SCR 186. 
only critically important jurisdictions which are essential to the existence of a superior court of inherent jurisdiction and to the preservation of its foundational role within our legal system." ${ }^{, 47}$ While the justices disagreed with respect to whether this jurisdiction was a "novel jurisdiction," all agreed that the act conferring such powers was constitutional.

Beyond constitutional constraints, legislatures have wide latitude in the structure and jurisdiction provided to new administrative bodies. ${ }^{48}$ Administrative law provides a range of protections within the confines of the statutory mandate, just as other statutes may provide minimum standards for administrative tribunals to follow (such as Ontario's Statutory Powers Procedure Act) unless exempted by statute. ${ }^{49}$ Just as the requirements of constitutional and administrative law must be kept in mind, so must the realities of scarce resources and competing government priorities. All tribunals require resources to achieve their mandates, but where those resources come from may vary. Some administrative bodies are funded by users (for example, securities commissions and law societies), while most will be funded by public revenues. Whatever the source of resources, the determination of a tribunal's budget has critical implications for its staffing, technological infrastructure, physical presence, and other key design features.

Against this backdrop, bifurcating the development of public authority and public administration in the context of administrative justice is a good example of a practice that is inconsistent with the very premise of design thinking and also seems to work against key principles of administrative law and key goals of government for more efficient and effective delivery of services in the broader public sector. For these reasons, I argue that the determination of the best model to address the needs, purposes, and principles of an administrative body must be a holistic enterprise, involving the expertise of policymakers and lawyers, administrators and information technology professionals, organizational and behavioural specialists, together with communication experts. All aspects of the tribunal experience should be considered together - that is, the statutory authority of the tribunal together with its physical and virtual presence, the budget and staffing of the tribunal together with its approach to proportionality or streaming of caseloads, and the rule making together with the strategies for accessibility, inclusion, and accommodations.

\section{PILOTS FOR EVALUATION, CONTINUOUS IMPROVEMENT}

Returning to the innovations of the design movement, the determination of the best model, and entrenching that model, together with the purposes and principles identified above, in legislation, does not the end the design process. In many ways, that legislation simply represents the point of departure for the most valuable part of the design process - the testing of effectiveness of the model by users and the adjustments/adaptations made in light of that evaluative process. For administrative justice, the evaluative process has been notably absent. ${ }^{50}$ Whether undertaken by tribunals, clusters of tribunals

$47 \quad$ Ibid at para 56.

48 For a discussion, see Ocean Port, supra note 24. See also Philip Bryden, "Structural Independence of Administrative Tribunals in the Wake of Ocean Port" (2003) 16 Can J Admin L Prac 125.

49 RSO 1990, c S-22.

50 For discussion, see S Hoffman \& L Sossin, "The Elusive Search for Accountability: Evaluating Adjudicative Tribunals" 
themselves, outside evaluators, or the government itself, the metrics and methods for assessing the effectiveness of administrative justice are remarkably under-developed, though initiatives such as the COAT framework (and its antecedents in user satisfaction surveys) have at least put evaluation on the radar in Canada. I believe design thinking advances this search for ways of evaluating the success of administrative justice providers.

In the following sections, I explore how this proposed framework might be used in relation to specific tribunal settings and assess recent initiatives involving the design of administrative justice. I consider as case studies the new Ontario model for auto insurance disputes within the License Appeal Tribunal [LAT], the Safety Licensing Appeals and Standards Tribunals Ontario [SLASTO], the recently established federal Administrative Tribunal Support Service [ATSSC], and a proposed new model for guardianship dispute resolution explored by the Law Commission of Ontario.

\section{A. The LAT and Auto-Insurance Disputes in Ontario}

In 2012, the Ontario government announced a review of its auto insurance dispute resolution system. ${ }^{51}$ The review was intended to address a number of challenges identified with the existing model (administered through the Financial Services Commission of Ontario [FSCO]). The review was called against a backdrop of continuously rising settlement amounts for auto insurance disputes, a doubling in the number of mediation applications between 2007-2008 and 2011-2012 with no appreciable rise in the number of motor vehicle accidents over this period, and escalating numbers of cases going to the courts from the FSCO, resulting in additional cost and delay to the parties.

The review, undertaken by Douglas Cunningham, former associate chief justice of the Superior Court for Ontario, commenced in 2013. Following extensive stakeholder consultations (which can often mean hearing more from counsel and industry representatives than actual claimants), Cunningham issued a set of design principles for the new dispute resolution model that he would be recommending:

- timeliness (access to resolutions should be quick and not require the intervention of the courts);

- proportionality (varying processes should be available based on the varying complexity of cases);

- accessibility (claimants should be able to access the system without difficulty with or without counsel);

- predictability (in other words, parties should be able to predict outcomes in accordance with a reasonable range based on transparent principles);

- streamlining (in other words, as little paper and process as possible)

- costs (in other words, a cost-effective model with as little possibility for gaming and abuse as possible); and

- culture (a culture of early dispute resolution should be encouraged). ${ }^{52}$

(2010) 28 Windsor YB Access to Justice 343.

51 See Douglas Cunningham, Final Report: Ontario Automobile Insurance Dispute Resolution System Review (February 2014), online: $<$ http://www.fin.gov.on.ca/en/autoinsurance/drs-final-report.pdf $>$.

52 Ibid at 3 . 
While not framed as "design thinking" and not following the methodology set out above for continuous user feedback, Cunningham's Automobile Insurance Dispute Resolution System Review [AIDRS Review] nonetheless reflects a shift in culture in administrative justice towards a more responsive, adaptable, and user-centric approach and, for these reasons, merits attention.

Based on these principles, and subsequent to further consultations and analysis, Cunningham recommended moving the AIDRS Review from the FSCO to the LAT, streamlining a number of stages into a new more comprehensive settlement conference, introducing video conferencing and other new technologies to enhance easier and more cost-effective access as well as a number of other important changes reflective of a design shift to a user-centred focus. ${ }^{53}$ The recommendations of the AIDRS Review were adopted and incorporated into new legislation passed in Ontario in 2015. As of 1 April 2016, accident benefit arbitration applications were received by the LAT rather than by the FSCO. ${ }^{54}$ The process is similar in some respects, but some changes have been made to the AIDRS in order to make the dispute resolution process more streamlined and, as a result, more user-friendly. ${ }^{55}$

The major change to the process is the removal of the mandatory mediation in advance of arbitration. An applicant is now able to apply to the LAT for his or her benefit immediately upon that benefit being denied or terminated. All parties and their representatives will be required to attend a case conference, at which all preliminary issues will be dealt with, settlement will be discussed, the type of hearing will be decided, and a hearing date will be set. If the matter does not settle at the case conference, the hearing will proceed as scheduled. The LAT has a hybrid approach to its adjudicative phase, which may involve written or in person hearings. Expedited, electronic hearings (for example, telephone hearings) are expected for most other disputes, while in-person hearings are reserved for the most serious cases such as catastrophic impairment determination. Written and electronic options are available at the FSCO but are rarely used except for simple motions. The LAT intends that in-person hearings will be held only when necessary. ${ }^{56}$

When handled by the FSCO, most disputes with insurers are resolved in mediation, and claimants have the option to proceed to trial if a settlement has not been reached. Under the new system, a formal mediation step has been removed, and most claims will be resolved prior to adjudication through a case conference aimed at settlement. ${ }^{57}$ The time required to settle a dispute will now be under 120 days in most cases. ${ }^{58}$ As well, the LAT has kept the user experience in mind as they have indicated that the new

53 Ibid, Appendix A, setting out the list of recommendations by the review.

54 I disclose that I served as chair of an Advisory Committee established by the Attorney General to provide input into the transition of auto insurance dispute resolution from the Financial Services Commission of Ontario to the License Appeal Tribunal. This role ended on 31 May 2016. None of the views expressed in this article reflect the discussions or positions of that Advisory Committee.

55 McCague Borlack, “Goodbye FSCO, Hello LAT” (February 2016), online: <http://mccagueborlack.com/emails/articles/lat-coming.html>.

56 Ibid.

57 Taverniti Vashishth, "Comments on Changes on the License Appeal Tribunal Regarding Insurance Disputes" (30 May 2016), online: <http://torontospersonalinjurylawyer.com/taverniti-vashishth-llp-comments-changes-licence-appealtribunal-regarding-insurance-disputes/>.

58 Ibid. 
form for filing an application for arbitration will be simplified, and they hope to eventually accept electronic filings and fee payment. ${ }^{59}$

One area of the new model that has been subject to criticism is the removal of the right of users to sue for accident benefits disputes in the Superior Court of Justice. ${ }^{60}$ Rather, users have the option first to seek a reconsideration and, subsequently (or if a reconsideration is not held), to request a "judicial review" by the Divisional Court of a LAT decision if dissatisfied, or they can appeal within thirty days on the basis of a legal mistake. Although the new process has limited some user options, this has been done in conjunction with increasing the efficiency and simplicity of the overall process. This dynamic reflects the trade-offs that often characterize the design approach and the importance of purposes and principles. If the protection of the rights of those involved in motor vehicle accidents is paramount, then the ability to sue for accident benefits in court should be the priority. On the other hand, if just, fair, and expeditious settlements are the goal, then limiting rights to sue advances important design goals.

The design of the AIDRS has followed a two-stage approach - while user feedback was sought in the phase of developing the model, it also informed the implementation of the model. The AIDRS is more commonly known as Automobile Accident Benefit Services [AABS]. Phase 2 is known as the Transition and Full Implementation Phase and will take place over the next eighteen to twenty-four months (from 1 April 2016). This phase will focus on the following:

- continuation of phased recruitment approach;

- delivery of e-filing;

- completion of case management system;

- performance indicators and data analysis;

- workflow analysis and long-term resource assessment; and

- operational policy and planning capacity and supports.

Based on the framework I develop above, it is possible to assess the auto insurance dispute resolution process fairly clearly (though its implementation is in the early stages and so a final evaluation is premature). The government decision to launch the AIDRS Review and the conduct of that review reflects attentiveness to needs assessment, stakeholder involvement, and the articulation of purposes and principles, though it also highlights the challenge of incorporating user voices in those early stages of the process. The process likely would receive relatively high scores on these aspects of the framework. The AIDRS Review provides relatively little guidance on the public administration aspects of the new model, which have been left largely with the LAT and the SLASTO cluster to determine, and there are no clear mechanisms for evaluation, assessment, and revision. The process likely would receive low scores on these aspects of the design framework.

The discussion above also highlights the kind of questions that design thinking adds to the conversation about administrative justice - not just in relation to individual tribunals but also with respect to the sector as a whole (at least within particular federal or provincial/territorial and municipal

59 McCague Borlack, supra note 52.

60 Miller Thompson, "The AB Alphabet Soup's New Letters - SLASTO and LAT” (5 February 2016), online:

$<$ http://www.millerthomson.com/en/blog/ontario-insurance-litigation-blog/the-ab-alphabet-soups-new-letters-slasto $>$. 
jurisdictions.) For example, should support services for administrative bodies be designed across the sector to capture economies of scale and address unevenness between large and small tribunals by centralizing administrative tribunal services or should such services be customized to the distinct needs of each tribunal. This dilemma resulted in a recent restructuring of administrative tribunal support at the federal level. As discussed below, I believe a design framework along the lines set out above may provide an effective framework with which to evaluate this new scheme.

\section{B. Administrative Tribunals Support Service of Canada}

In 2014, Parliament passed the Administrative Tribunals Support Service of Canada Act, which is intended to usher in a new era of modernization and efficiency in the operation of administrative justice in Canada ${ }^{61}$ Interestingly, the Act contains no mention of any purpose in the creation of the new support service or a mandate for its activities. The news release upon the passage of the Act is somewhat more informative. The government indicates the benefits of the new structure:

Benefits of this change:

There are several benefits to consolidating the provision of support services for these administrative tribunals, including the following:

- Improving capacity to meet the administrative needs of tribunals

Many of these tribunals are small organizations with limited resources. Tribunals themselves have identified access to support as an on-going challenge, in some cases, due to their size. The ATSSC will bring together staff and consolidate resources in a single, integrated organization that will strengthen the capacity to support tribunals' needs. For example, some tribunals may currently rely on one person for all their human resources services; the ATSSC will provide access to a broader range of specialized employees in areas such as staffing, labour relations and training.

- Improved access to justice for Canadians

A centralized organization will be able to better use technology and implement best practices to aid access to justice through modernized operations. Some benefits could include a more widespread use of the following:

- video conferencing for hearings and other alternative options to in-person interaction, to offer greater flexibility for those appearing before the tribunals; and

- comprehensive Web content about processes, past decisions or any other information relevant to the public that may require the services of a tribunal.

\footnotetext{
${ }^{61}$ SC 2014, c 20, s 376.
} 
The ATSSC will contribute to improving the efficiency and effectiveness of the tribunals' decisionmaking processes - an important component of access to justice.

\section{- Efficiencies through economies of scale}

Efficiencies can be achieved by sharing some resources and having a centralized and versatile team with administrative and other expertise. ATSSC employees possess a broad range of skill sets and expertise that will help meet the support service needs of the tribunals and will ensure consistency across tribunals. Moreover, the ATSSC will also provide an opportunity to share best practices among previously separate organizations. Many tribunals have identified support challenges in their annual reports and see partnerships and the sharing of resources as a means to address operational limitations. ${ }^{62}$

The ATSSC is responsible for providing support service to eleven federal administrative tribunals by way of a single, integrated organization. ${ }^{63}$ Services include the specialized services required by each tribunal (for example, registry, research and analysis, and legal and other case-specific work) as well as corporate service (for example, human resources, financial services, information technology, accommodations, security, and communications). By creating this one single body to provide support for these administrative tribunals, the government aims to improve the capacity and become more operationally efficient in order "to better meet the administrative needs of federal tribunals and to improve access to justice for Canadians." ${ }^{.64}$ The ATSSC will focus on improving management practices and controls by increasing the use of common processes and systems, standardizing internal services processes, adopting new technologies, making better use of facilities, reducing the need for outsourcing services, and identifying other cost-saving efficiencies that will achieve results and value for resources. Improving the capacity to meet the administrative needs of tribunals contains elements of a humancentred approach. Many of the tribunals are small organizations with limited resources, and support is an ongoing challenge due to their size. ${ }^{65}$ As the ATSSC brings together staff and consolidates resources in a single, integrated organization that will strengthen the capacity to support tribunal needs, this could possibly translate to a more efficient and accessible process for users. As well, a centralized organization may be able to better use technology and implement best practices to aid access to justice through modernized operations. Some benefits could include a more widespread use of video conferencing, which would offer greater flexibility for users of the tribunals, and comprehensive online content about processes, past decisions, or any other information relevant to the user's experience.

Although the consolidation may improve the user experience, it is important to note that the change is largely motivated by minimizing costs through creating efficiencies and eliminating the duplication of

62 Government of Canada, "News," online: <http://news.gc.ca/web/article-en.do?nid=897239>.

63 Government of Canada, "Administrative Tribunals Support Service of Canada," online:

$<$ https://www.canada.ca/en/administrativetribunalssupportservice/index.html?_ga=1.172215587.1829801473.146660354 $9>$.

64 Government of Canada, "Administrative Tribunals Support Service of Canada: 2015-15 Report on Plans and Priorities," online: <https:/www.canada.ca/en/administrative-tribunals-support-service/transparency/rpp20152016.html>.

65 Government of Canada, "News," supra note 59. 
facilities. ${ }^{66}$ As well, there are concerns about potential conflicts of interests, which could have a negative effect on the user's experience. Specifically, inclusion of the Canadian International Trade Tribunal [CITT] could expose decisions to allegations of conflicts of interest as foreign trading partners and domestic industry claimants who appear before the CITT often have Department of Justice lawyers opposing them. ${ }^{67}$ CITT staff that collect data, conduct investigatory research, and assist in drafting the decisions would therefore be employed by the same Department of Justice.

Additionally, the process by which this significant reform was developed appears to be at odds with the design framework set out above. The government announced the change through an omnibus budget bill that meant almost no time for debate or discussion of its terms or implications. ${ }^{68}$ Among others, University of Ottawa law professor Errol Mendes suggests that the new agency fundamentally changes a critical piece of Canada's administrative justice and legal system and "shouldn't be rammed through in budget legislation without proper analysis and debate." ${ }^{69}$ He also notes that the chief administrator of the new agency under the Act is appointed by the government and serves "at pleasure." In light of the lack of any apparent needs assessment or collective and consultative process around the purposes and principles of the new service, not to mention an absence of a discussion of the optimal model for supporting tribunals, it is likely the new service, whatever its potential merits for the operation of the sector or particular tribunals, would score poorly against the design framework set out above.

Beyond what works for a particular tribunal or for an administrative justice sector more broadly, design thinking also may inform the analysis of whether certain kinds of dispute resolution should remain with the courts (or a government department) or be integrated into a tribunal. This context is explored below in relation to the area of guardianship over vulnerable individuals in Ontario.

\section{Should Dispute Resolution Move from Courts to Administrative Tribunals: The Case of Guardianship?}

The Law Commission of Ontario [LCO] recently considered this issue in relation to disputes over capacity and guardianship for vulnerable individuals (whether due to illness or disability) that are currently resolved through the Superior Court of Ontario. ${ }^{70}$ The LCO consulted broadly among groups representing users and found that for those directly affected by the laws relating to capacity disputes, "the ability to be meaningfully heard on issues that affect their lives is central to their wellbeing. In

66 Geoffrey C. Kubrick, "Penny Wise, Pound Foolish? Federal Government Proposes to Combine 'Back Office' Work of Eleven Federal Tribunals and Boards into One New 'Mega' Administrative Agency" (June 2014), online:

$<$ http://www.mcmillan.ca/Penny-Wise-Pound-Foolish-Federal-Government-Proposes-to-Combine-Back-Office-Workof-Eleven-Federal-Tribunals-and-Boards-into-One-New-Mega-Administrative-Agency>.

67 Ibid

68 See Kathryn May, "Super Agency for Federal Tribunal Raises Concerns," Ottawa Citizen (1 April 2014), online: $<$ http://o.canada.com/uncategorized/super-agency-for-federal-tribunals-raises-concerns $>$.

69 Ibid.

70 Law Commission of Canada (LCO), Legal Capacity, Decision-Making and Guardianship, Final Report (March 2017), online: $<$ http://www.lco-cdo.org/en/our-current-projects/legal-capacity-decision-making-and-guardianship/final-report/>. 
evaluating mechanisms for access, the key consideration is whether the proposed forum provides a meaningful, expert and accessible determination." ${ }^{, 71}$ As the LCO explains,

our clients want their day in court. What that court is, is to be determined. But it should be more sensitised and almost individualised to our clients. Clients just want to be heard and if the CCB does it, great, Superior Court does it, but I wish there was a mechanism where everybody could be pleased that, you know, they've had a fair hearing, everybody had their fair say and a decision was reached. And that's, sort of, part of the recovery process. ${ }^{72}$

As the LCO observes, the Superior Court of Justice process is perceived to be complex, costly, time consuming, and intimidating. The court processes are not well suited to the needs of unrepresented individuals. Families and individuals often feel unable the navigate the system without costly legal assistance, and the system may be challenged to keep the individual who lacks, or may lack, legal capacity at the centre of the process. In short, effective dispute resolution is seen as beyond reach for many.

In its analysis, the LCO explores the most practical and effective dispute resolution options, including the option of creating a tribunal encompassing the jurisdictions of the Ontario Consent and Capacity Board and the Superior Court of Justice in this area. The LCO's final recommendation will build in part on a 2016 submission from the Advocacy Centre for the Elderly [ACE], which emphasized the enhanced accessibility of tribunals in relation to courts:

The courts are not the forum in which these types of cases can be dealt with most efficiently. In ACE's experience, guardianship applications brought through the courts can take many months, and, in contested applications, years. The costs can be significant and, where the assets of the incapable person are not similarly significant, it may not be practical, cost-effective or proportionate for a person of modest means to apply for guardianship over an incapable person.

ACE receives many calls from family members who are being denied access to an older adult by an attorney for personal care. ACE assists only the older adult in these circumstances. The only remedy available for these family members, if negotiation is not possible, is to take the attorney to court and seek directions on the power of attorney for personal care or apply for guardianship. The legal fees involved place these options beyond the means of many people. Most importantly, the allegedly incapable person does not have easy access to the courts. Where the dispute regards a guardian of property or an attorney for property, the funds necessary to bring an application on one's own behalf are

71 Law Commission of Canada (LCO), “Legal Capacity, Decision-Making and Guardianship,” Interim Report (October 2015), online: <http:/www.lco-cdo.org/capacity-guardianship-interim-report.pdf> [LCO, "Legal Capacity"].

72 LCO, “Appendix E: Focus Groups, 2014 Public Consultations" (25 September 2014), online: <http://www.lcocdo.org/en/capacity-guardianship-interim-report-appendixE>. 
likely in the control of the attorney or guardian. If the allegedly incapable person cannot access their own funds, they cannot hire a lawyer. Nor is it likely that this person would have the ability to represent himself or herself in a complicated guardianship matter.

An administrative tribunal offers accessibility and flexibility. Guardianship proceedings could be resolved in weeks rather than in months or years. Applications for directions need not be as prohibitively expensive as going to court. Further, at an administrative tribunal, a simple application made by telephone by the allegedly incapable person could trigger the appointment of counsel, thus ensuring representation for this person. ${ }^{73}$

Ironically, the key risk cited by the LCO in designing a tribunal rather than a court-based dispute resolution pathway is the risk of the tribunals becoming "judicialized," which describes the trend in some tribunals towards more court-like, formal, and costly procedures. ${ }^{74}$ This concern over ossification must be anticipated in the design process as well. A culture of innovation, experimentation, and continuous improvement is difficult to sustain. With this in mind, the evaluation of tribunal design must consider not only the operational features of tribunals but also their resilience, adaptability, responsiveness, and flexibility in the face of changing user needs, changing technology, and changing approaches to an optimal user experience.

While it is too early to determine how this proposed new (or expanded) tribunal would measure up according to the design framework set out above, it is noteworthy to see the user-centred design thinking underlying the LCO's analysis. It is also worth exploring what other settings, currently ill-suited to formal adjudication in courts, might benefit from multi-disciplinary or more flexible dispute resolution options in a tribunal or regulatory setting, such as family justice disputes. The brief case studies discussed above show both examples of the culture shift towards user-centred administrative justice design and the resilience of a more conventional top-down fragmented model of developing administrative justice.

\section{CONCLUSIONS}

In this article, I have explored the implications of human-centred design for the development of administrative justice and, in particular, for new or reformed tribunals. Based on the influence of design thinking, I have set out a proposed framework for evaluating tribunal reform, based on the extent to which this process is user-centred and also consistent with the distinct public interest purposes and principles that animate administrative justice. I have applied this framework in the context of recent tribunal reform initiatives as part of a growing effort to establish evaluative criteria for administrative tribunals.

73 See Advocacy Centre for the Elderly, Submission (3 March 2016), online: $<$ http://www.advocacycentreelderly.org/appimages/file/ACE\%20LCO\%20submissions\%203Mar2016.pdf>.

74 LCO, "Legal Capacity," supra note 67, citing Judith McCormack, "Nimble Justice: Revitalizing Administrative Tribunals in a Climate of Rapid Change” (1995) 59 Sask L Rev 385 at 5-6, 9-10. 
We are living through a transitional period in the development of administrative justice. While it is not clear how long the journey will take or how much can and will change along the way in how the public sector works, I believe design frameworks will transform how we think about administrative justice and its effectiveness for users. This transformation, in turn, will lead to tribunals and other administrative bodies that look and act differently and, I hope, better meet the needs of users - and the public - in the future. 